\title{
Terarquía de centros según flujos de personas en el área metropolitana de Monterrey
}

\author{
Ernesto Quintanilla R.
}

\begin{abstract}
El propósito de este trabajo es investigar si en la actualidad existen uno o más subcentros que desconcentren las actividades comerciales y de servicios en el área metropolitana de Monterrey (AMM). Para ello se aplica la técnica de Nystuen y Dacey (a través de la cual se recurre a la teoría de grafos para la identificación de regiones nodales), utilizando la información proveniente de una encuesta de origen y destino de pasajeros, realizada en 1981 en esa area metropolitana.

El trabajo explica cómo se ha utilizado la técnica de análisis y describe, asimismo, los resultados de su aplicación. Se llega a la conclusión de que todas las zonas en que se divide el AMM están subordinadas al centro principal, lo cual demuestra que se trata de una ciudad muy centralizada, con un subcentro ya consolidado y otros dos subcentros incipientes. Se termina afirmando que el AMM se encuentra inmersa en un proceso de transición de una ciudad monocéntrica a una policéntrica, proceso que acompaña al gran crecimiento físico, demográfico y económico experimentado por la misma.
\end{abstract}

\section{Antecedentes}

En las obras científicas relacionadas con la economía urbana en general, y con el crecimiento urbano en particular, existe consenso en cuanto a que, a lo largo de su desarrollo, las áreas urbanas evolucionan del monocentrismo al policentrismo; es decir que, si bien en sus orígenes y en las fases tempranas de su desarrollo una determinada ciudad cuenta con un solo centro que aloja las principales actividades comerciales, de servicios y frecuentemente también las manufactureras, a medida que aumenta la población residente y se amplían los límites de la ciudad (en otras palabras, a medida que la ciudad "crece"), surgen en forma simultánea deseconomías de aglomeración en el centro y economías de aglomeración en otros lugares ubicados dentro de la ciudad. Estas consideraciones tienen una lógica sencilla: primero, el creciente número de personas que residen en el centro de la ciudad y que utilizan los servicios ubicados en el mismo, aunado a la escasa posibilidad de que el centro se extienda de forma horizontal (para esto tendría que competir favorablemente con otros usos del suelo urbano ya establecidos en sus inmediaciones), producen un aumento considerable en la densidad de población de esta zona - un "crecimiento hacia arriba" - con el consiguiente incremento en una serie de elementos de costo, tales como transporte, rentas, construcción y dotación de servicios infraestructurales. Segundo, el aumento de la población residente en otras áreas de la ciudad significa tanto una expan- 
sión en la demanda por bienes y servicios privados como un crecimiento en la demanda por el establecimiento de servicios infraestructurales en las mismas. En etapas más avanzadas del desarrollo urbano pueden surgir también fuentes de empleo alternativas a las que ofrece el centro de la ciudad, con lo cual surgen y se fortalecen subcentros dentro de la misma área urbana con un alto grado de autonomía con respecto al centro primario.

A primera vista, éste parece ser el caso de Monterrey, que a partir de 1940 ha estado experimentando un crecimiento acelerado tanto en su población, como en su actividad económica y su extensión geográfica. Así, mientras que en 1960 la población total en el área metropolitana de Monterrey (AMM) era de 708399 habitantes, residentes en los municipios de Garza García, Guadalupe, Monterrey, San Nicolás de los Garza y Santa Catarina, para 1970, incorporándose en ese año al AMM los municipios de Apodaca y General Escobedo, el total de habitantes era de 1242558. Para 1980, la población total ascendía a 1988012 personas (García, 1986). Esto implica un crecimiento de $80.63 \%$ en los 20 años, es decir, una tasa media anual de crecimiento poblacional de aproximadamente $5.2 \%$. Es bien sabido que al menos la mitad de este crecimiento se debe al componente migratorio. Al respecto, García (1986) escribe: "En 1980 la población migrante que recibió el estado fue de 425180 personas. Con respecto a la población total (2 513 044) el porcentaje fue de 16.92\%. . .' De ese total de migrantes recibidos por Nuevo León, el AMM recibió $88.51 \%$. Las entidades federativas que aportan los mayores contingentes migratorios, no sólo durante el periodo 1970-1980, sino tradicionalmente son, en orden de importancia, San Luis Potosi, Tamaulipas, Coahuila y Zacatecas.

Por lo que respecta al crecimiento económico, podemos examinar los índices de producción manufacturera, de consumo de energía eléctrica y de carga transportada por ferrocarril disponibles para el AMM (Centro de Investigaciones Económicas UANL, 1977 y 1984), correspondientes al periodo 1960-1983. Entre 1960 y 1970, el índice de producción industrial total -que es un índice de cantidad-aumentó $151 \%$; el índice de producción de bienes no duraderos aumentó $122 \%$, en tanto que el de bienes durareros experimentó un incremento de 164\%. Para el periodo 1970-1980, el crecimiento observado en estos indicadores fue, respectivamente, de 88,148 y 65 por ciento. Sin embargo, entre 1980 y 1983 , tanto el índice total como el de bienes duraderos sufrieron un descenso: de 472 a 430 y de 435 a 363, respectivamente. El índice de producción de bienes no duraderos experimentó sólo un ligero aumento, de 550 a 570 .

En cuanto a los índices de carga transportada por ferrocarril, encontramos que el de volumen total en 1983 era de 262 (siendo 1960 el año base); el índice de carga total ingresada al AMM en ese mismo año era de 369 , en tanto que el de carga total egresada era de 77 . Conviene aclarar que estos tres índices incluyen la información correspondiente a la carga 
de productos agrícolas. Podemos concluir que, mientras que el total de carga ingresada casi se cuadruplica, el total de carga egresada permanece aproximadamente constante a lo largo del periodo de referencia. Esto era de esperarse dado que, por una parte, el crecimiento en el total de carga de productos agrícolas ingresada al AMM es función directa del crecimiento de la población, en tanto que la carga de productos agrícolas egresados es mínimo. Por otra parte, es fácil aceptar la idea de que la mayor parte de los productos manufacturados egresados del AMM es transportada por carretera.

Un tercer indicador del crecimiento económico urbano es el índice de consumo de energía eléctrica, que entre 1960 y 1983 experimentó un incremento de $381 \%$. El índice de consumo industrial de electricidad aumentó, durante el mismo periodo, $341 \%$, mientras que el índice agregado del consumo de gobierno, doméstico y comercial aumento 687 por ciento.

Que en este lapso Monterrey ha experimentado un notable proceso de crecimiento físico, demográfico y económico, resulta entonces indudable. Tal vez un poco menos evidente, pero no menos cierto, es que también se ha formado y consolidado una serie de subcentros al interior de esta área urbana, los cuales han funcionado para desconcentrar las actividades comerciales y de servicios, especialmente en lo que se refiere a las transacciones al menudeo. Una evidencia estadística de este fenómeno nos la aportan las cifras correspondientes a las tasas medias anuales de crecimiento intercensal de la población en los municipios que componen el AMM, a saber (García: 1986); Apodaca, 9.31\%; Garza García, 8.88\% ; General Escobedo, 16.35\%; Guadalupe, $12.02 \%$; San Nicolás de los Garza, $10.06 \%$; Santa Catarina, 10.17\%. Monterrey, que es el centro del área urbana, experimentó solamente un modesto crecimiento de $3.02 \%$, cifra muy inferior a la correspondiente a cualquiera de los demás municipios. Lo que no resulta tan claro es si alguno de los subcentros ubicados en tales municipios ha sido capaz también de constituirse en un proveedor de empleos alternativo al centro primario. El propósito del presente trabajo es, entonces, investigar si en la actualidad existen uno o más subcentros que presenten las características que se han estado comentando.

\section{Marco teórico}

La forma en que nos proponemos responder la interrogante recién planteada es mediante la inspección de la estructura de orígenes y destinos del tranporte de pasajeros en el AMM.

La información disponible para el efecto es la Encuesta sobre el Transporte Urbano levantada en el año de 1981 por el Centro de Investigaciones Urbanísticas de la UANL, así como la matriz de orígenes y destinos 
generada por dicha investigación. Mediante un trabajo posterior de validación (Quintanilla, García y de la Garza, 1983) de la información disponible en la matriz de orígenes y destinos, se generó una matriz reducida, en la que el AMM se subdividió en 33 zonas de origen y destino; aquí utilizamos precisamente esta matriz reducida, en virtud de que la información contenida en ella presenta mayor calidad estadística.

Puesto que el problema inmediato es estudiar una estructura espacial de carácter nodal y llegar a identificar la existencia de uno o más polos de atracción de los viajes (es decir, nodos), consideramos que una técnica adecuada es la de Nystuen y Dacey (1961), que consiste en la aplicación de la teoría de grafos para la identificación de regiones nodales. El problema consiste en subdividir un área geográfica determinada en dos o más subáreas que presenten características suficientes para ser regiones nodales. ${ }^{1}$ Según Richardson (1979), las regiones nodales son aquellas "donde la cohesión es el resultado de flujos, contactos e interdependencias internos generalmente polarizados hacia un centro dominante o nodo".

Si bien Nystuen y Dacey aplican su técnica al caso de regiones, donde las diferentes áreas urbanas ubicadas en una determinada región pueden considerarse como los puntos en un grafo y sus interacciones pueden identificarse como líneas, a escala intraurbana las diferentes zonas en que se subdivide una ciudad no pueden, en sentido estricto, ser consideradas como puntiformes, dado que, por una parte, la identificación del centroide de cada zona generalmente es arbitraria y, por otra, la forma en que sean trazados los límites de las zonas es también una cuestión de criterio. De estos dos factores depende la dirección y la magnitud de las interrelaciones (flujos) de las zonas, fenómeno que no ocurre a escala regional. Esto constituye una limitación al presente trabajo. Sin embargo, para el caso concreto de Monterrey, la limitación no es demasiado restrictiva. Puesto que se trabaja con información relativa a flujos interzonales de personas, basta delimitar correctamente las áreas de vivienda. Además, dado que los datos se refieren a flujos totales, no se requiere identificar los centroides de las zonas. Consideramos que las áreas de vivienda están identificadas adecuadamente, ya que se utilizan los límites de las áreas geoestadísticas básicas identificadas para propósitos censales; dichos límites están casi siempre trazados en función de accidentes topográficos que rompen efectivamente la continuidad de las áreas.

Hechas estas salvedades, pasamos a describir la técnica de Nystuen y Dacey.

En resumen, la técnica utiliza información relacionada con flujos económicos entre pares de unidades geográficas básicas para determinar la dirección y el grado de interacción de tales pares de unidades; de esta ma-

1 “'La región nodal describe la relación entre la zona de influencia, que es un área y la ciudad central o nodal, que es puntiforme. . ." Nystuen y Dacey (1961:31). 
nera se busca identificar las redes de interacción económica que existan dentro del espacio (área urbana, en este caso) bajo estudio, agrupando así las unidades geográficas básicas en subáreas del área urbana total.

De acuerdo con Nystuen y Dacey (1960:30), "las regiones nodales se definen evaluando los contactos externos de pequeñas unidades de área. Cada una de estas unidades de área es asignada a aquel lugar con el que tiene la asociación dominante. Generalmente, ésta será una ciudad próxima, y esta ciudad se define como el lugar central o punto nodal para las áreas unitarias que se orientan hacia él. La agregación de estas áreas unitarias, a su vez, se denomina la región nodal. . .". Para estos autores, entonces, la "asociación dominante" es "el concepto crítico al definir una estructura nodal. Las restantes asociaciones no dominantes no se utilizan, aun cuando las magnitudes de algunas de estas asociaciones pudieran ser relativamente grandes"' (idem: 31).

Nystuen y Dacey definen la región nodal "sobre la base del flujo más fuerte que emana de o que se mueve hacia cada una de las áreas unitarias en la vecindad de un lugar central. La región está delimitada por la agrew gación de estos elementos individuales. La jerarquía de lugares centrales que se determina por la agregación de los lugares centrales más pequeños, los cuales dependen de un solo centro mayor para las funciones que no posee. Este entrelazamiento de ciudades define la organización de redes de ciudades y la posición de cada ciudad dentro de la red" (idem: 32).

Partiendo de la información sobre flujos entre pares de puntos (áreas básicas) se forma una matriz de flujos o interrelaciones, es decir:

$$
X=\left[x_{i j}\right] \quad i, j=1,2, \ldots, n
$$

donde $x_{i j}$ es el valor numérico que toma el flujo que se genera en el punto o área $i, y$ tiene como destino el punto o área $j$ (convencionalmente, los elementos diagonales, $x_{i i}$, se igualan a cero).

Nystuen y Dacey expresan: "dentro de la miríada de relaciones que existen entre ciudades, la red de flujos máximos será la que trace el esqueleto de la organización urbana en toda la región". Por "flujos máximos" entendemos el valor más alto de entre todos los flujos que se originan en un punto determinado. En el caso de la matriz de flujos definida en (1), el flujo máximo de cada columna será el elemento máximo de la misma, donde la matriz nos muestra el número de viajes generados en la zona hilera y que tienen como destino la zona columna. Este concepto se utiliza para identificar las zonas que se encuentran asociadas a una zona central; en otras palabras, se trata de encontrar el conjunto de zonas subordinadas al lugar central.

Ahora bien, los lugares centrales (o "zonas centrales" en nuestro caso) se identifican empleando tres propiedades que poseen los flujos máximos: 1) Se dice que una zona es independiente cuando su flujo máximo 
es hacia una zona de menor jerarquía; 2) los flujos máximos son transitivos, es decir, si la zona a es subordinada de b y ésta es subordinada de $c$, entonces a es subordinada de $c$, y 3 ) una zona no puede ser subordinada de ninguna de sus zonas subordinadas.

Conceptos adicionales son el de "flujo nodal" (el flujo máximo que parte de una zona subordinada) y la "estructura nodal" (el conjunto de los flujos nodales). Finalmente, la demostración de dos teoremas asegura la validez de la subdivisión del territorio en regiones y la correcta identificación de los lugares centrales. Los teoremas en cuestión son: 1) "Los componentes de una estructura nodal realizan la participación del conjunto de zonas", y 2) "Cada componente de una estructura nodal tiene un lugar central único (punto terminal)."

Hasta aquí se ha tratado de identificar y evaluar las relaciones directas entre pares de áreas. Es decir, solamente se han cuantificado los flujos máximos tomando en consideración los viajes directos entre pares de zonas. En términos de la gráfica, sólo se han medido los flujos que se originan en $a$ y se trasladan directamente a $b$. Es necesario también tomar en cuenta los flujos $a-c-b$, así como los flujos $a-d-b$ y sumarlos a los flujos $a-b$ para cuantificar correctamente la magnitud de la relación entre a y $b$; es decir, debemos agregar los flujos indirectos a los flujos directos para obtener los flujos totales.

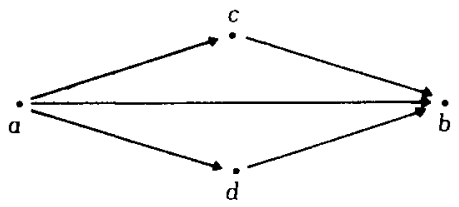

Se describe a continuación el procedimiento para lograr tal propósito.

Primero se requiere normalizar los datos originales mediante la conversión de los elementos $x_{i j}$ en $y_{i j}$, donde

$$
y_{i j}=\frac{\mathrm{x}_{i j}}{\text { Máx } \sum_{j} \mathrm{x}_{i j}},
$$

es decir, se obtiene el total-columna máximo de la matriz de flujos y se dividen todos los $x_{i j}$ entre este total. Los valores $y_{i j}$ así generados satisfacen las siguientes desigualdades:

$$
\begin{array}{ll}
0 \leq \mathrm{y}_{i j}<1 & \mathrm{i}, j=1,2, \ldots, \mathrm{n} \\
0<\sum_{j} \mathrm{y}_{i j} \leq 1 & j=1,2, \ldots, n
\end{array}
$$


donde la igualdad $\sum_{j} y_{i j}=1$ sólo se cumple para Máx $\sum_{j} y_{i j}$. Es conveniente notar que los valores $y_{i j}$ están expresados en decimales.

De esta manera, la matriz $Y$ es la matriz de datos normalizados generada a partir de la matriz de datos originales $X$. La matriz $Y^{2}$, resultante de multiplicar Y. Y, contiene todos los flujos de longitud 2 (es decir, todos aquellos flujos que pasan por un punto intermedio, tales como $a-c-b$ y $a-$ d-b en la gráfica).

Así tenemos que

$$
Y^{2}=\left[a_{i j}\right]
$$

donde

$$
a_{i j}=\sum_{k}\left(y_{i k}\right)\left(y_{k j}\right) \quad k=1,2, \ldots, n
$$

En el ejemplo de la gráfica, tendríamos

$$
a_{a b}=y_{a c} y_{c b}+y_{a d} y_{d b}
$$

La suma de $Y+Y^{2}$ nos proporciona el total de flujos directos más indirectos de la longitud 2 , es decir,

$$
y_{i j}+\sum_{k}\left(y_{i k}\right)\left(y_{k j}\right)
$$

Asimismo, sería necesario agregar los flujos de longitud 3, longitud 4, etc. Es decir, $Y^{3}, Y^{4}, \ldots$, formando la matriz

$$
B=Y+Y^{2}+Y^{3}+\ldots Y^{n}+\ldots
$$

Los elementos de $\mathrm{B}, b_{i j}$, representan el flujo total, directo e indirecto, del lugar $i$ al lugar $j$.

El cálculo de la matriz B se facilita empleando una regla elemental de álgebra. La serie infinita de la ecuación (8) se convierte entonces en:

$$
B=(I-Y)^{-1}-i
$$

donde I es la matriz identidad. Si bien (9) está tomada directamente de Nystuen y Dacey (p. 38), podemos notar que las expresiones $(I-Y)^{-1}$ $(I-Y)^{-1}$ son en realidad equivalentes, pues los elementos de la diagonal principal no tienen significado (serían los flujos de una zona hacia la misma zona) y, por lo tanto, no importa si son ceros o unos. 


\section{Identificación de la jerarquía}

Según la información presentada en el cuadro 1 , donde se asienta la matriz de flujos interzonales de transporte de pasajeros [matriz $X$, ecuación (1) de la sección anterior], de las 33 zonas en que se dividió el AMM para su estudio, 24 tienen como destino de su flujo máximo a la zona 12, que incluye dentro de sus límites el centro comercial, administrativo y habitacional tradicional de la ciudad de Monterrey. Aquí se fundó la ciudad (1596) y, hasta principios del siglo actual, aquí se encontraba alojada prácticamente la totalidad de la población del municipio.

Ahora bien, de las ocho zonas que no dependen directamente de la zona 12, cuatro presentan su flujo máximo a la zona 1, que es un área de gran extensión física ubicadia en el extremo noroeste de la mancha urbana, pero incluida dentro de los límites municipales de Monterrey; de hecho puede afirmarse que esta zona es la que ha experimentado la expansión más notable en actividades 'omerciales, habitacionales, manufactureras y administrativas, en una co.nbinación que no deja de guardar cierto equilibrio.

Las zonas 20 y 21 , por su parte, son subordinadas de la 22: esto resulta lógico, ya que esta última contiene el importante núcleo manufacturero y administrativo de San Nicolás de los Garza, mientras que en aquéllas se encuentran localizadas áreas residenciales, principalmente; muchos de estos residentes tienen su lugar de trabajo precisamente en las empresas manufactureras asentadas en la zona 22 .

La zona 14 resulta ser subordinada de la zona 26: mientras que en la primera encontramos un predominio casi absoluto de viviendas, ya dentro del municipio de Guadalupe, en la segunda está localizado el centro tradicional administrativo, comercial y de servicios de ese municipio. Por lo tanto, la relación de subordinación encontrada es consistente con la realidad. Algo similar ocurre con el caso de la subordinación de la zona 32 a la 23: en la primeras se encuentran localizadas fundamentalmente áreas habitacionales, mientras que en la segunda existe una diversificación mayor de actividades, con lo cual se puede constituir en zona de destino de viajes relacionados con el trabajo o con actividades comerciales o educativas.

La subordinación de la zonas 4,7 y 8 a la zona 1, es también un resultado fácilmente comprensible, ya que son áreas en su mayor parte habitacionales, mientras que la última, como ya se expresó, no es un área más diversificada y dinámica. La relación que no resulta tan lógica a primera vista es la subordinación de la zona 33 a la 8 , en vista de que existen dos zonas intermedias y de que la zona 8 es limítrofe con la zona 12.

Es posible notar que, directa o indirectamente, todas las zonas se encuentran subordinadas a la 12, incluso las zonas 1, 22, 23 y 26 . Esta información nos presenta el panorama de un área metropolitana fuertemente 


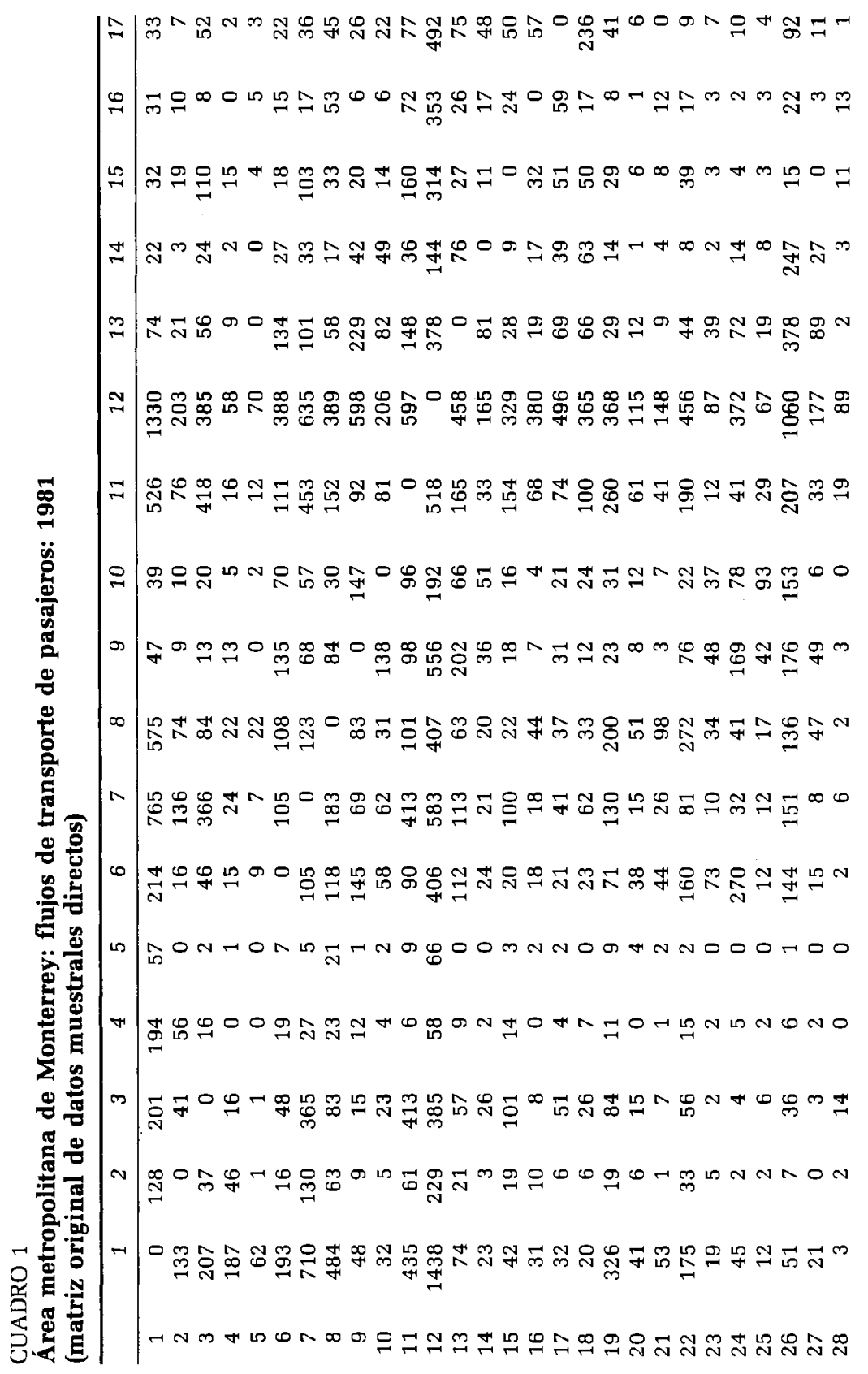




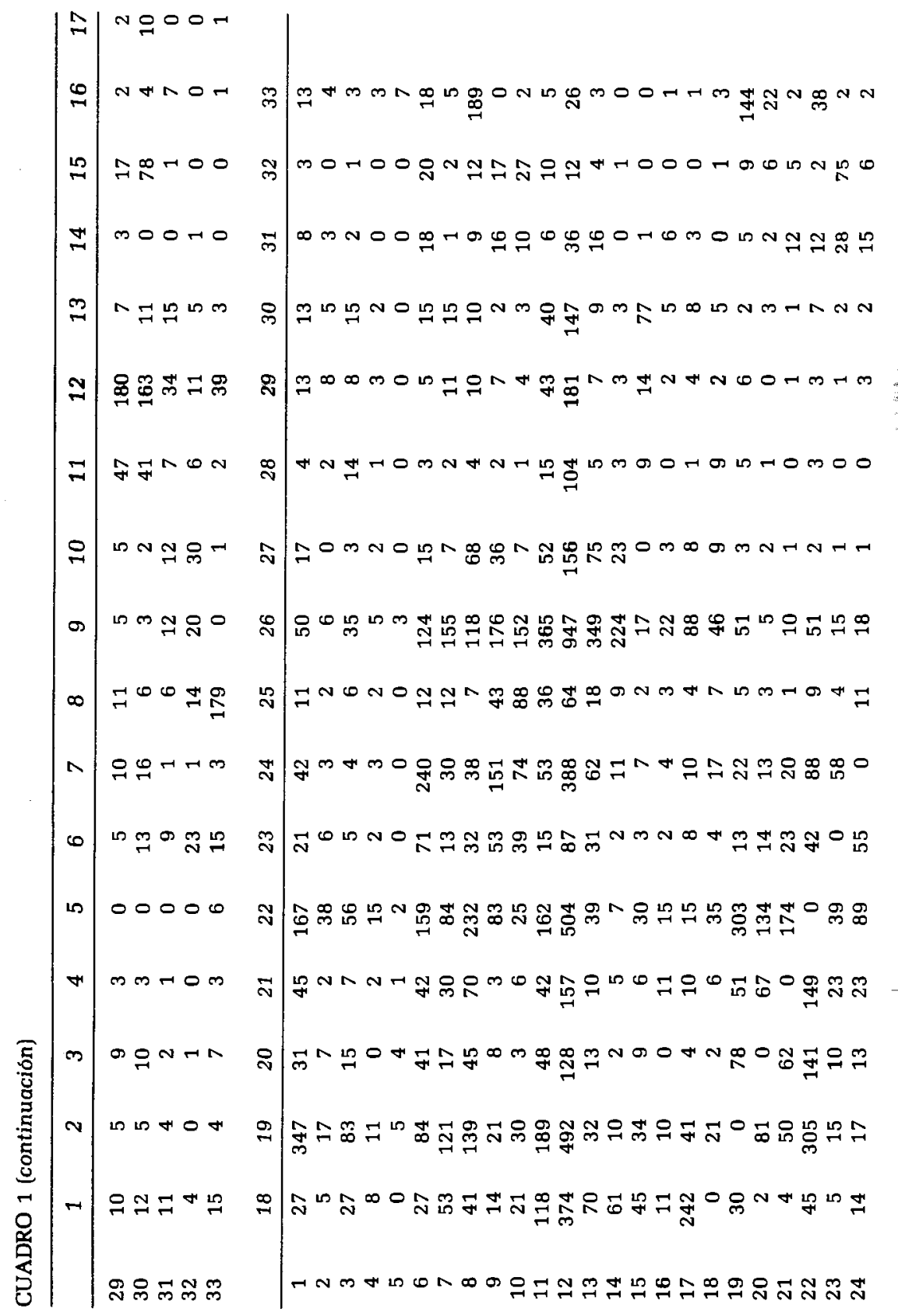


ESTUDIOS DEMOGRÁFICOS Y URBANOS

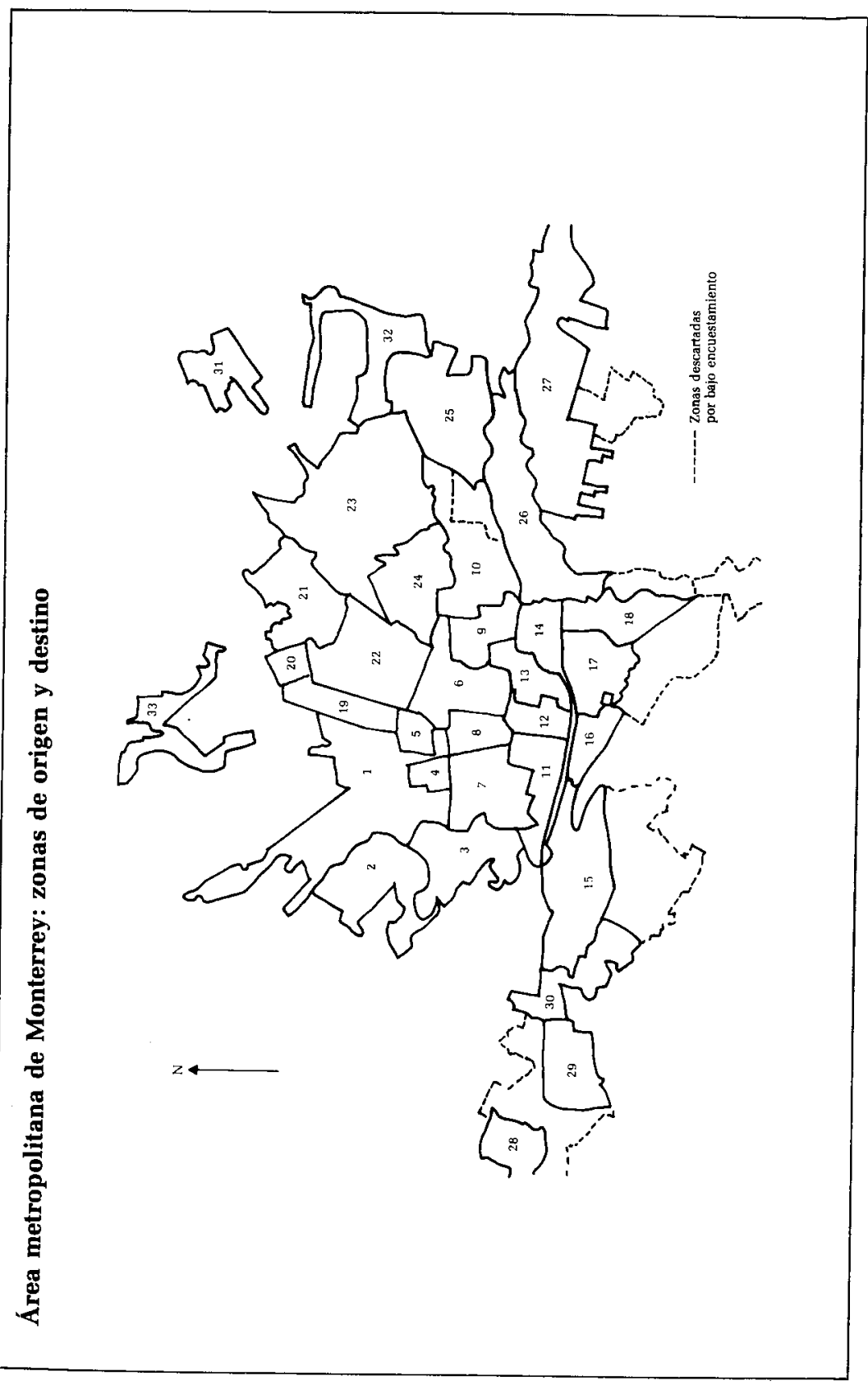




\section{Grafo nodal de flujos directos}

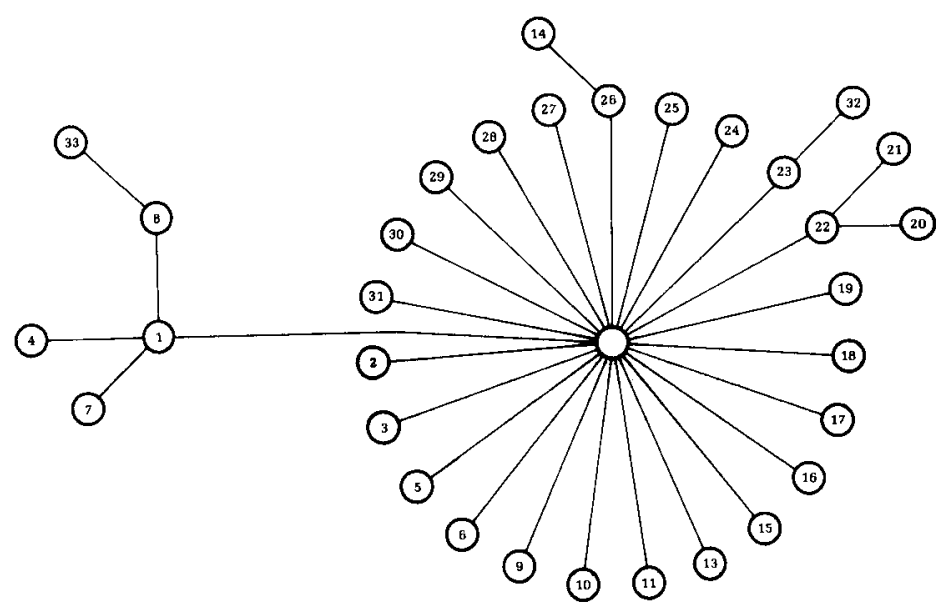

\section{Grafo nodal de flujos totales}

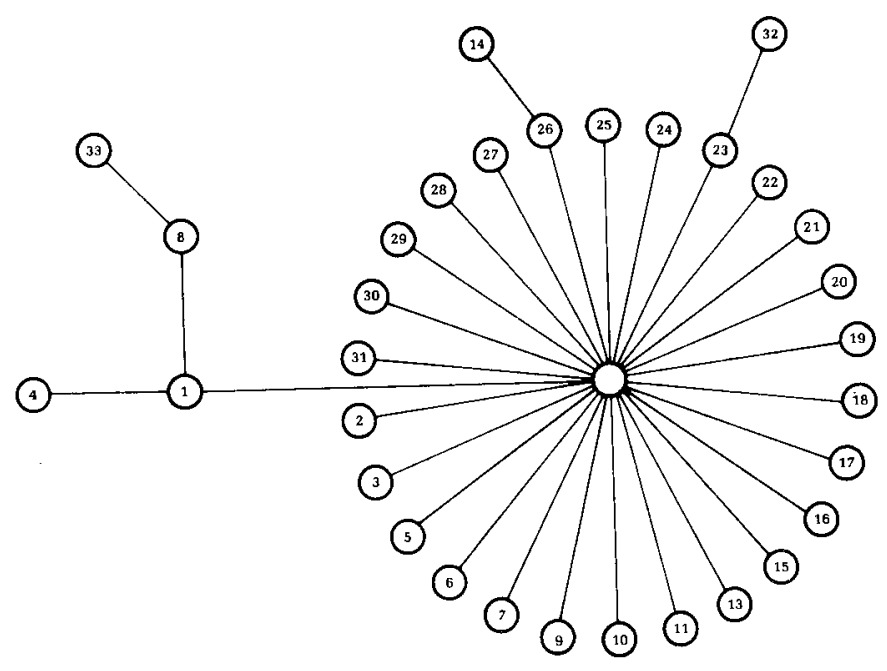


centralizada, con una incipiente aparición de subcentros, especialmente en el caso de la zona 1. El grafo nodal asociado a la matriz $X$ (de flujos directos) representa esta situación con mayor claridad.

De acuerdo con el procedimiento establecido, a partir de la matriz $X$ se obtuvo la matriz de datos normalizados o matriz $Y$. Puesto que esta última no es más que una transformación aritmética de la matriz $X$, la información que nos aporta sobre la estructura nodal de Monterrey es, por lo tanto, idéntica a lo ya expuesto. Es, asimismo, innecesario presentar la matriz $Y$.

Caso diferente es el del cuadro 2, que presenta la denominada matriz $B_{1}$ cuyos elementos $b_{i j}$ incluyen los datos normalizados de los flujos totales, es decir, los directos más los indirectos, entre pares de zonas. En esta ocasión la situación de una ciudad altamente polarizada es aún más clara, dado que solamente cinco zonas no están directamente subordinadas a la zona 12; las zonas 4, 8 y 33 siguen estando subordinadas a la 1, en tanto que la zona 14 es aún dependiente de la 26 , y la 32 lo es de la 23. Persiste, según se puede observar, la relación de subordinación de la zona 33 con la 8 , lo cual sería motivo de un examen más minucioso. El grafo nodal correspondiente nos indica un área con un centro dominante, un subcentro ya consolidado (zona 1) y dos subcentros incipientes, que son las zonas 23 y 26 .

\section{Conclusión}

Como es ya evidente, la información analizada sobre flujos interzonales de transporte de pasajeros nos conduce a concluir que el AMM se encuentra en la actualidad inmersa en un proceso de transición de una ciudad monocéntrica a una policéntrica. Existe ya un subcentro consolidado y se encuentran en vías de consolidación dos más. Dado que el crecimiento demográfico, económico y espacial de esta área está garantizado, al menos por los próximos 20 o 25 años (si bien se espera que las tasas anuales de crecimiento presenten una tendencia general a la baja), podemos confiar en que la ciudad continuará este proceso de descentralización de las actividades humanas, incluyendo los mercados laborales. Las políticas de regulación urbana, de construcción de capital económico y social de infraestructura, y de dotación de servicios públicos deberán tomar en consideración este fenómeno. 


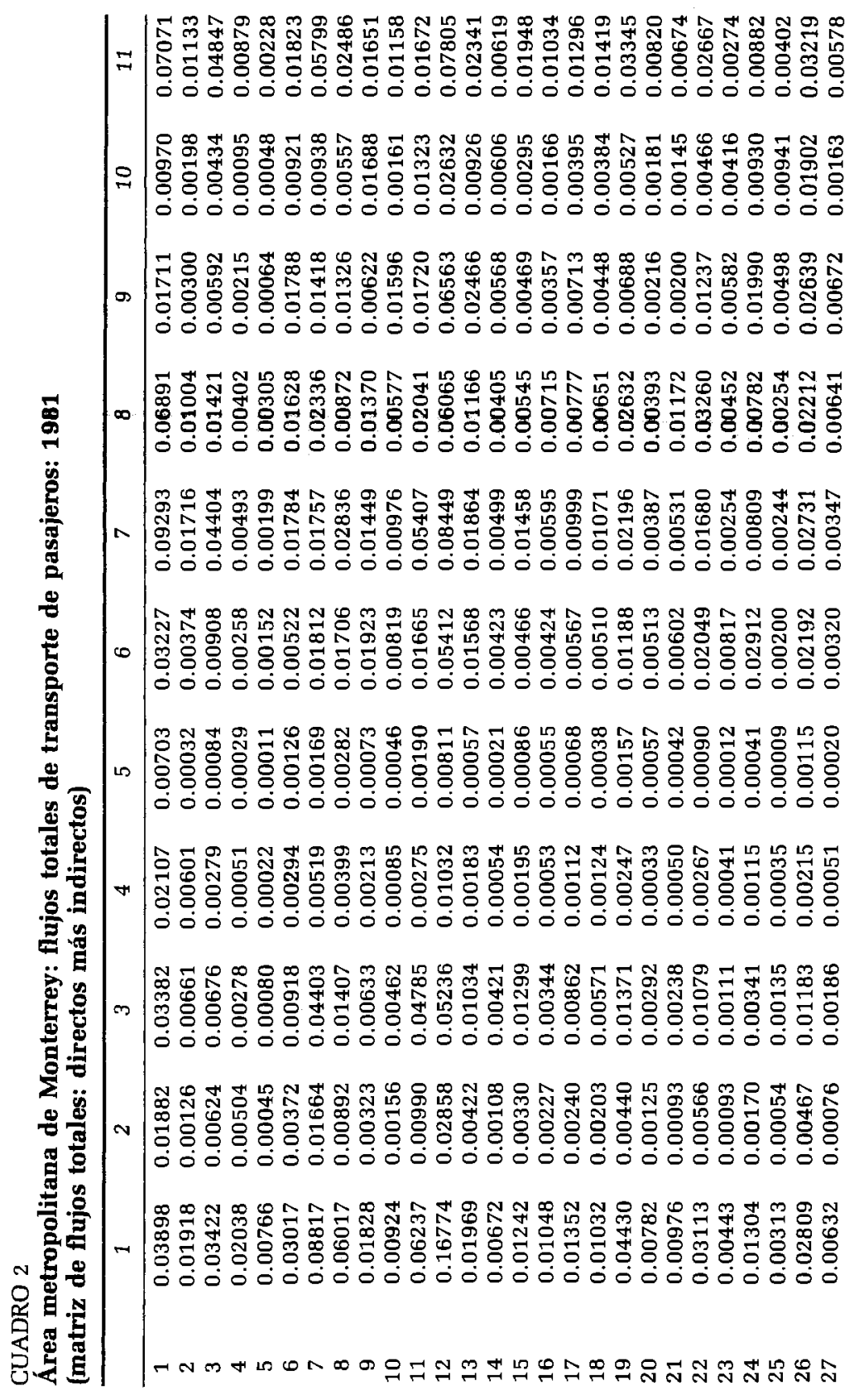




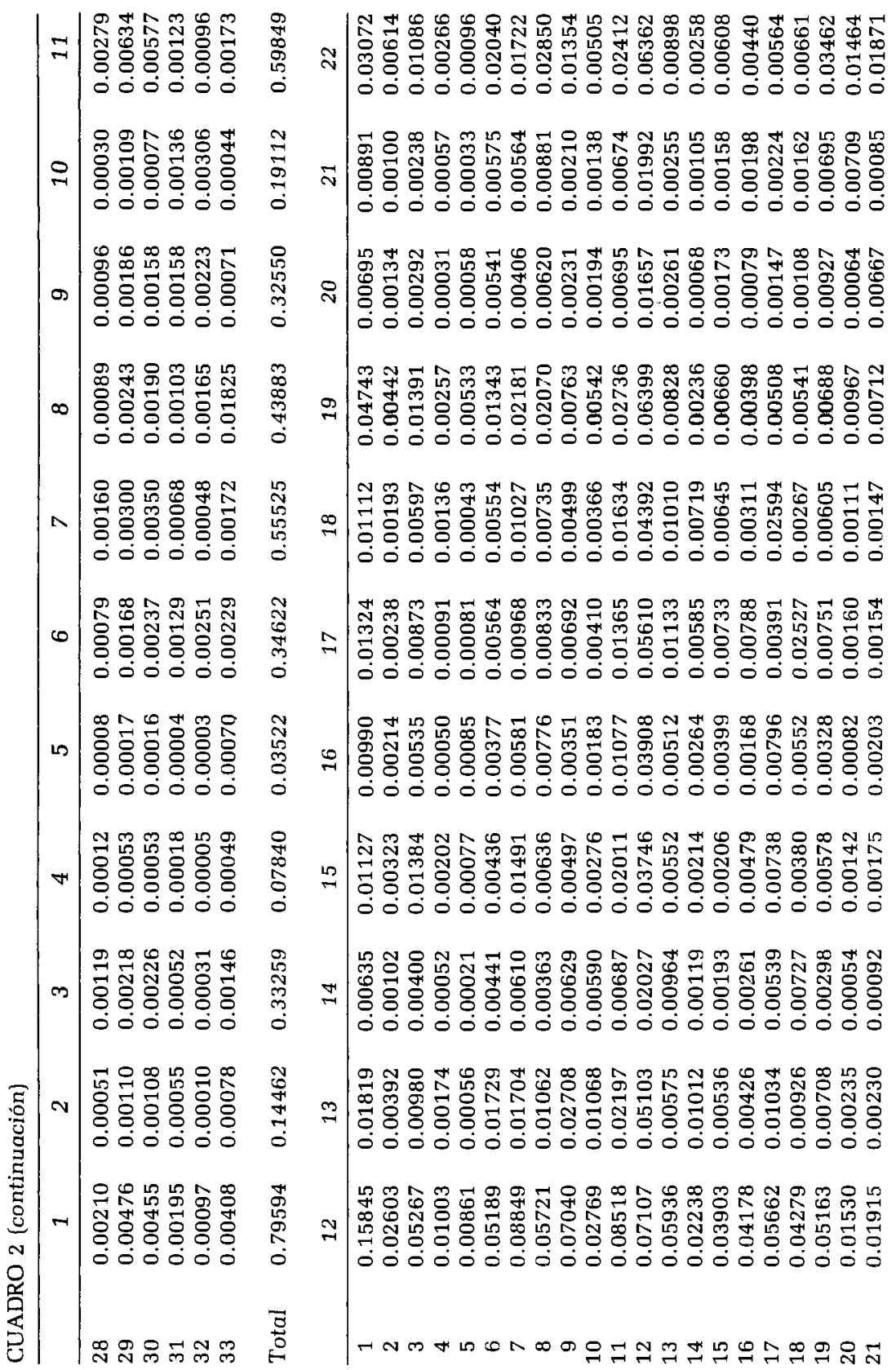




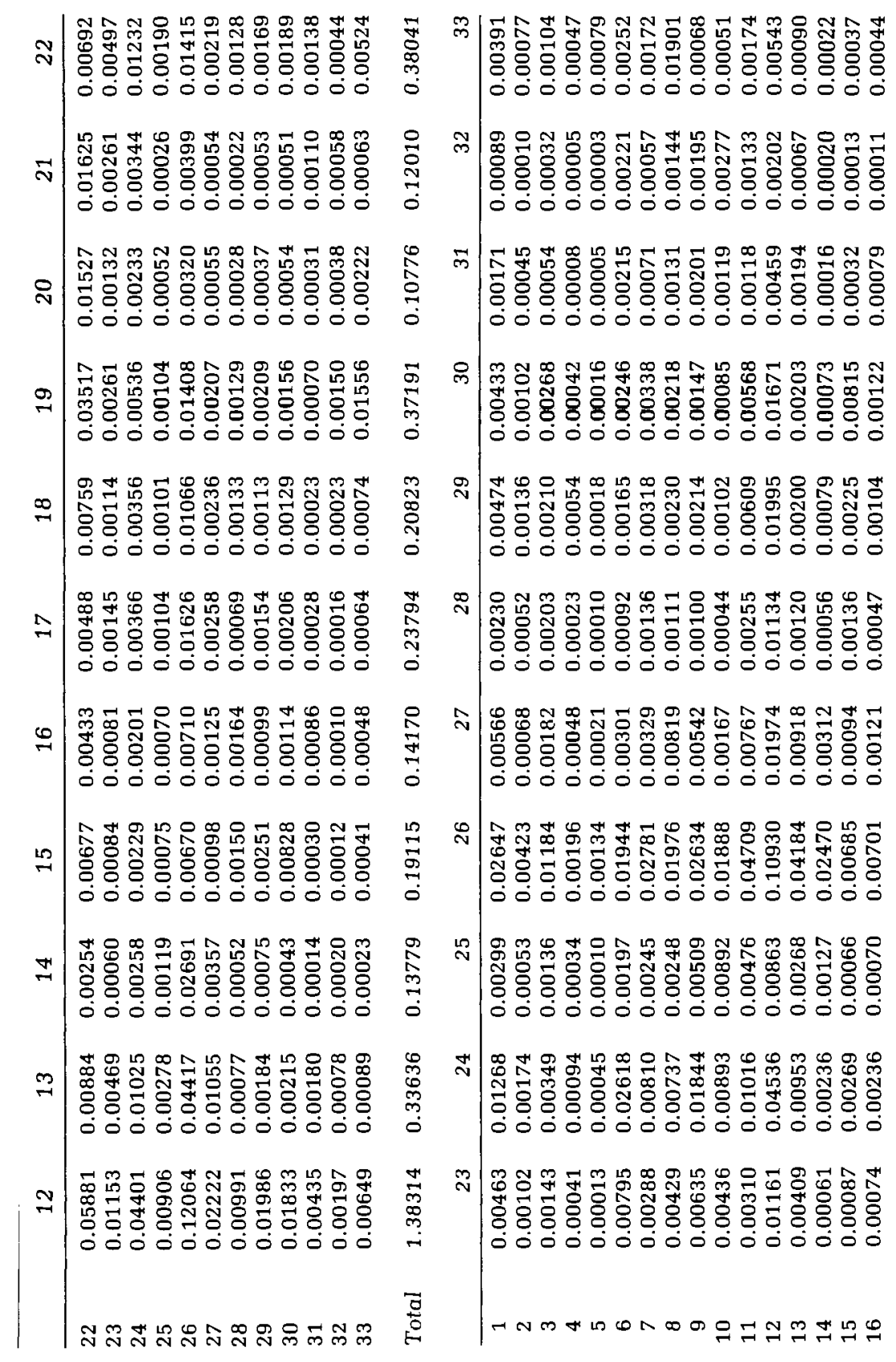




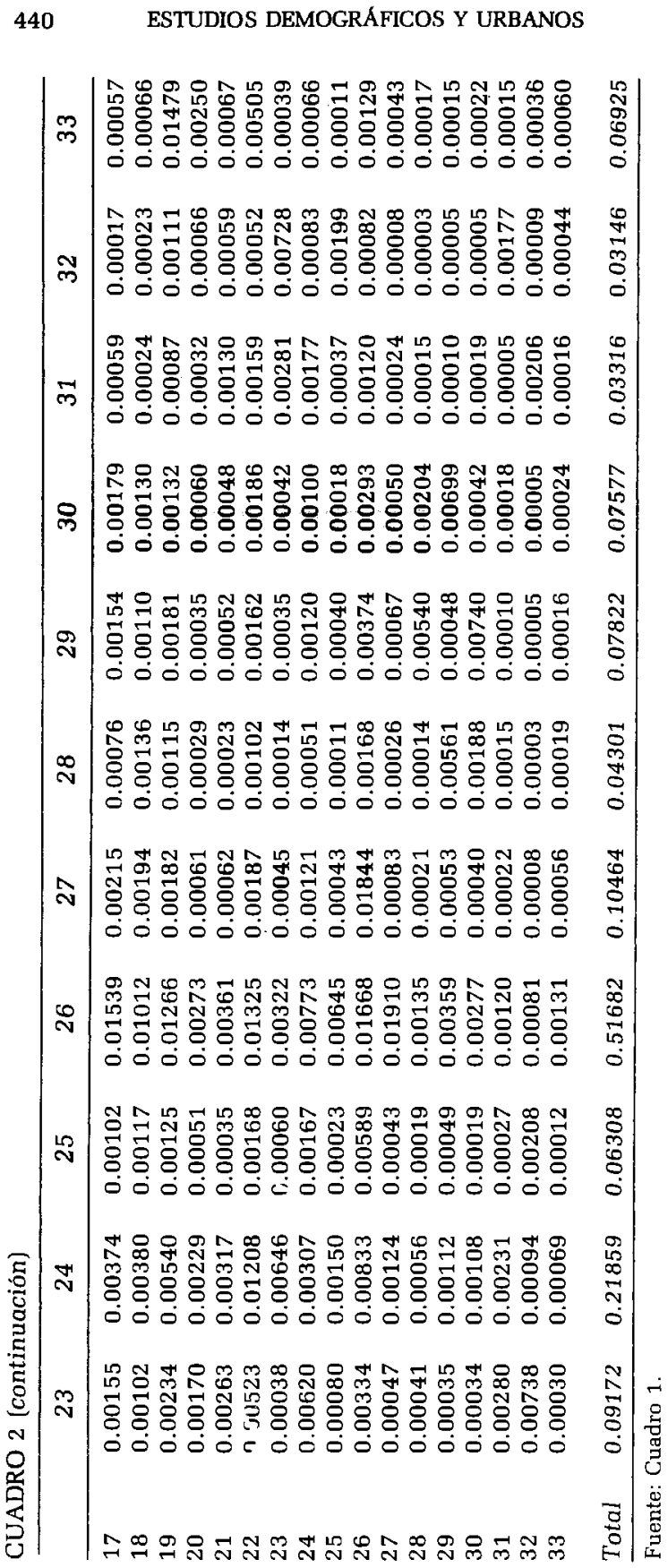




\section{Bibliografia}

Centro de Investigaciones Económicas, UANL (1977), Boletín bimestral, vol. XV, núm. 87. (1984), Boletín bimestral, vol. XXII, núm. 129.

Centro de Investigaciones Urbánisticas, UANL(1981), "Matriz de origen y destino del transporte urbano en el área metropolitana de Monterrey", Monterrey.

García Cavazos, A.R. (1986), Nuevo León: indicadores demográficos y de bienestar social: 1960-1970-1980, UANL, Monterrey.

Nystuen, J. D. y M. F. Dacey (1961), "A Graph Theory Interpretation of Nodal Regions", en Papers and Proceedings of the Regional Science Association, vol. 7, 29-42.

Quintanilla, E., A. R. García y R. de la Garza (1983), Estudio del transporte urbano en el área metropolitana de Monterrey: nivel diagnóstico, UANL-Conacyt, Monterrey.

Richardson H.W. (1979), Regional Economics, University of Illinois Press, Urbana Illinois. 
